\title{
The use of organic biostimulants in hot pepper plants to help low input sustainable agriculture
}

\author{
Andrea Ertani, Paolo Sambo, Carlo Nicoletto, Silvia Santagata, Michela Schiavon and Serenella Nardi
}

\begin{abstract}
Background: World demand for agricultural products is increasing. New insights are required in order to achieve sufficient and sustainable yields to meet global food request. Chemical fertilizers have been studied for almost 200 years, and it is unlikely that they could be improved. However, to produce food for a growing world population, various methods to increase the efficiency of chemical fertilizers are investigated. One approach to increasing crop productivity is the development of environment-friendly organic products named biostimulants which stimulate plant growth by enhancing the efficiency of chemical fertilizers. Most studies have tested these products in short-term experiments, but little information is available on their effect on plants at the maturity stage of growth. On this account, this paper focuses on the effects of two biostimulants, red grape skin extract (RG) and alfalfa hydrolyzate (AH), throughout the entire plant development.
\end{abstract}

Results: The findings obtained in the present investigation demonstrate the effectiveness of RG and AH in improving growth and the nutritional value of peppers. Specifically, the two biostimulants increased the phenol concentration, antioxidant activity, and ascorbic acid concentration in fruits, as well as the capsaicin concentration in plants. Differences in effectiveness between RG and AH were likely related to the characteristics of the starting matrixes as well as to the industrial processes used for their production. The efficiency of RG and AH in promoting plant growth and yield could also be due to their content in indole-3-acetic acid (IAA), isopentenyladenosine (IPA), phenols, and amino acids.

Conclusions: In the light of these results, the application of biostimulants could be considered as a good strategy for obtaining high yields of nutritionally valuable vegetables with lower environmental impact.

Keywords: Peppers; Biostimulants; Endogenous hormones; Phenols; Antioxidants

\section{Background}

The climate changes occurring in recent years have affected the farming, imposing constraints and objectives frequently ignored in the past. The environmental question and quality of the products affect farmers' choices in different ways, depending on the specific vulnerability of the environment where the crops are cultivated [1]. In this context, crop-derived food safety and nutritional value have become important issues worldwide [2]. For example, there is increasing interest in studying and quantifying the antioxidant and anti-inflammatory constituents of plants in terms of their potential health benefits $[3,4]$.

\footnotetext{
* Correspondence: andrea.ertani@unipd.it

Department of Agronomy, Animals, Food, Natural Resources and Environment - DAFNAE, University of Padua, Viale dell'Università 16, 35020, Legnaro, Padova, Italy
}

To increase the content of nutritional constituents in plants, many approaches have been studied to increase plant nutrients capture and yield such as genetic selection, which has included allele selection, gene and genome duplication, and new genotypes creation. However, despite the advantages that these techniques offer, some of them may also pose potential problems for food safety and require special attention in order to ensure consumer health protection $[5,6]$.

On this account, the use of biostimulants in agricultural practices is proposed as a safe tool to enhance the nutritional properties of food crops. Biostimulants are recognized as environment-friendly compounds with beneficial effects on plants $[7,8]$. In particular, they decrease the use of mineral fertilizers by increasing the amount of micro- and macro-nutrients taken up by plants, positively influencing root morphology and plant growth $[9,10]$. They also display hormone-

\section{黑 Springer}


like activity and influence plant metabolism by interacting with biochemical processes and physiological mechanisms, such as glycolysis and nitrogen assimilation $[11,12-13]$.

The mechanisms behind the physiological and biochemical effects of biostimulants on plants are often unknown, because of the heterogeneous nature of the raw materials used for their production. Furthermore, these effects are often the result of many components that may work synergistically in different ways.

Recent studies suggest that active molecules contained in biostimulants can promote nitrogen assimilation through stimulation of the activity and transcription of $\mathrm{N}$ assimilation and Krebs' cycle enzymes [7-11]. Furthermore, the induction of the metabolic pathway associated with the synthesis of phenylpropanoids in plants treated with biostimulants may explain why these products can help plants to overcome stress situations $[14,15]$. In particular, a protein hydrolyzatebased fertilizer obtained from alfalfa hydrolyzate plants (AH) was proved to help maize plants to overcome salinity stress through stimulation of enzymes functioning in nitrogen metabolism, enhancement of phenylalanine ammonia-lyase (PAL) activity and transcription, and increase of flavonoid synthesis [16]. PAL is an important enzyme that catalyzes the first committed step in the biosynthesis of phenolics by converting phenylalanine to trans-cinnamic acid and tyrosine to p-coumaric acid, opening the way to the secondary metabolism. The biostimulant activity of $\mathrm{AH}$ was related to the presence of triacontanol (TRIA) and indole-3-acetic acid (IAA), two important regulators of plant metabolism [15].

In recent studies, the application of products with biostimulant action to pepper plants was found to exert positive effects on plant growth and yield without loss of fruit quality $[13,17,18]$. Pepper is an important agricultural crop due to the nutritional value of its fruits, which are an excellent source of a wide array of phytochemicals with well-known antioxidant properties. The main antioxidant compounds include carotenoids, capsaicinoids, and phenolic compounds, particularly flavonoids, quercetin, and luteolin $[19,20]$.

Most of studies testing biostimulants analyze their effects on seed germination and plants growth in shortterm experiments, but little information is available on their effects at flowering and maturity stages of plants. On this account, the purpose of this investigation was to study the effects of two biostimulants on plant growth, phenological development, and some metabolic parameters of pepper plants (total phenols, ascorbic acid, capsaicin, dihydrocapsaicin), throughout the development from seedling to fruit.

\section{Methods}

\section{Characterization of the products}

The two products used in this study (red grape skin extract (RG) and $\mathrm{AH}$ ) were manufactured by ILSA (Arzignano-Vicenza, Italy). AH was produced by a fully controlled enzymatic hydrolysis using vegetal material from alfalfa (Medicago sativa L.) plants. The elemental composition, organic matter content, and physical properties of AH were previously reported by Schiavon et al. [7]. Specifically, the water percentage in $\mathrm{AH}$ was $43.5 \%$ $(v / v)$, and the amount of organic matter was low $37.6 \%$ $(w / v)$. The content of ash and the electrical conductivity $(\mathrm{ECw})$ were both high, with values of $18.9 \%(w / v)$ and 16 dS $\mathrm{m}-1$, respectively. The percentage of inorganic nitrogen in the form of ammonia and nitrates was low $(0.38 \%$ and $0.03 w / w$, respectively), whereas the total amount of free amino acids was high up to $1.916 \%(w / w)$ and correlated with the free $\alpha$-amino nitrogen $(\alpha-\mathrm{NH} 2-\mathrm{N})$. The hydrolytic process employed for EM production was effective in the weight-average molecular weight (MW) reduction, as confirmed by data on EM hydrolysis degree (DH) and MW.

RG was obtained from the skin of red grape wine via cool extraction according to the method of Machado [21]. RG aqueous extract was prepared by extracting $10 \mathrm{~g}$ of dried ground plant material with $50 \mathrm{~mL}$ of deionized water in a shaker for $2 \mathrm{~h}$ at room temperature. The extract was then filtered with cellulosic membrane filters at $0.8 \mu \mathrm{m}$ (Membra-Fil ${ }^{\circ}$ Whatman Brand, Whatman, Milan, Italy). The $\mathrm{pH}$ was determined in water $(3: 50 w / v)$. Total organic carbon (TOC) was measured using an element analyzer (varioMACRO CNS, Hanau, Germany).

Total phenols in RG extracts were determined according to Arnaldos et al. [22]. Specifically, RG $(1 \mathrm{~mL})$ was maintained in ice with pure methanol $(1: 1, v / v)$ for $30 \mathrm{~min}$ and centrifuged at 5,000 $\mathrm{g}$ for $30 \mathrm{~min}$ at $4{ }^{\circ} \mathrm{C}$. One $\mathrm{mL}$ of $2 \% \mathrm{Na}_{2} \mathrm{CO}_{3}$ and $75 \mu \mathrm{L}$ of Folin-Ciocalteau reagent (Sigma-Aldrich, St. Louis, MO, USA) were added to $100 \mu \mathrm{L}$ of phenolic extract. After 15 min of incubation at $25^{\circ} \mathrm{C}$ in the dark, the absorbance at $725 \mathrm{~nm}$ was measured. Gallic acid was used as standard according to Meenakshi et al. [23].

For reducing sugars determination, a sample of RG product was dried for $48 \mathrm{~h}$ at $80^{\circ} \mathrm{C}$, ground in liquid nitrogen, and then $100 \mathrm{mg}$ were extracted with $2.5 \mathrm{~mL}$ $0.1 \mathrm{~N} \mathrm{H}_{2} \mathrm{SO}_{4}$. Samples were incubated in a heating block for $40 \mathrm{~min}$ at $60^{\circ} \mathrm{C}$ and then centrifuged at $6,000 \mathrm{~g}$ for $10 \mathrm{~min}$ at $4^{\circ} \mathrm{C}$. After filtration $(0.2 \mu \mathrm{m}$, Membra-Fil ${ }^{\circ}$ Whatman Brand, Whatman, Milan, Italy), the supernatants were analyzed by HPLC (Perkin Elmer 410, Perkin Elmer, Waltham, MA, USA). The soluble sugars were separated through a Biorad Aminex $87 \mathrm{C}$ column $(300 \times 7.8 \mathrm{~mm}$; Bio-Rad Laboratories, Inc., 
Hercules, CA, USA) using $\mathrm{H}_{2} \mathrm{O}$ as eluent at a flow rate of $0.6 \mathrm{~mL} \mathrm{~min}{ }^{-1}$.

Indole-3-acetic acid (IAA) in the RG was determined using an enzyme-linked immuno-sorbent assay (ELISA) standardized with methylated IAA (Phytodetek-IAA, Sigma, St. Louis, MO, USA). The ELISA test utilized a monoclonal antibody to IAA and was sensitive in the 0.05-to-100 pmol range. The tracer and standard solutions were prepared following the manufacturer's instructions, and absorbances were read at $405 \mathrm{~nm}$ with a microplate reader (Bio-Rad Laboratories, Inc., Hercules, CA, USA).

Isopentenyladenosine (IPA) in RG and AH was determined by ELISA, a Phytodetek-IPA with an anti-IPA monoclonal antibody was used (Sigma-Aldrich, St. Louis, MO, USA). The competitive antibody-binding method was adopted to measure the IPA concentration. IPA labeled with alkaline phosphatase (tracer) was added with the sample to antibody coated microwells. A competitive binding reaction was set up between a constant amount of the IPA tracer, a limited amount of the antibody and the unknown sample containing IPA (SigmaAldrich, St. Louis, MO, USA). One hundred $\mu \mathrm{L}$ of standard IPA concentration or serial dilutions of RG and $\mathrm{AH}$ and $100 \mu \mathrm{L}$ diluted tracer were added to each well. For the standard curve, progressions of 100, 50, $20,5,1,0.1$, and $0.02 \mathrm{pmol}$ IPA $100 \mu \mathrm{L}^{-1}$ were used, whereas for RG and $\mathrm{AH}$, the progressions were 20, 10, $7.5,5.0,3.5$, and $2.5 \mu \mathrm{g} \mathrm{C} 100 \mu \mathrm{L}^{-1}$. After incubation at $4^{\circ} \mathrm{C}$ for $3 \mathrm{~h}$, the wells were decanted and any unbound tracer was washed out by adding $200 \mu \mathrm{L}$ of washing solution before adding $200 \mu \mathrm{L}$ of substrate solution for colorimetric detection. After $60 \mathrm{~min}$ at $37^{\circ} \mathrm{C}$, the optical density (OD) was read at $405 \mathrm{~nm}$ using a microplate reader (Bio-Rad Laboratories, Inc., Hercules, CA, USA).

\section{Experimental design and growth conditions}

The experimental trial was derived from the factorial combination of three types of treatment: no biostimulant, a cool extract from RG, and an AH. Two doses (50 and $100 \mathrm{~mL} \mathrm{~L}^{-1}$ for $\mathrm{RG}$, and 25 and $50 \mathrm{~mL} \mathrm{~L}^{-1}$ for $\mathrm{AH}$ ) of biostimulants were applied to two randomized blocks of pots, each consisting of 50 pots (ten pots per treatment to test biostimulants at flowering stage and ten pots per treatment to test biostimulants at maturity stage). The two doses for each biostimulant were in accordance with previous tests showing that doses in the 1-to- $200 \mathrm{~mL} \mathrm{~L}^{-1}$ range were those that more interfered with pepper metabolism. Each pot was filled with $2 \mathrm{~L}$ perlite/vermiculite mixture. At the beginning of the trial, 7-day-old seedlings of chili pepper (Capsicum chinense L. $c v$. Fuoco della Prateria) were transplanted at a density of one plant per pot. Plants were grown until maturity in a tunnel maintained at $25^{\circ} \mathrm{C} / 15^{\circ} \mathrm{C}$ day/night, receiving natural light. Plants were treated twice, i.e., at the second and fourth week after transplanting, by spraying each one with $4.5 \mathrm{~mL}$ of RG or AH on the leaves. All treatments were irrigated with a half-strength Hoagland's nutrient solution. Plants from 50 pots were sampled at flowering (4 weeks after transplanting), and plants from the remaining 50 pots at maturity (6 weeks after transplanting), harvesting leaves and fruits separately.

\section{Analysis of sugars in plant material}

Leaf and fruit samples $(2 \mathrm{~g})$ were homogenized in water $(20 \mathrm{~mL})$ with an Ultra Turrax T25 (IKA, Staufen, Germany) at 13,500 rpm until uniform consistency. Samples were filtered with filter paper (589 Schleicher) and further filtered through cellulose acetate syringe filters $(0.45 \mu \mathrm{m})$. The analysis of the extracts was performed using an HPLC apparatus (Jasco X.LC system, Jasco Co., Tokyo, Japan) consisting of a model PU-2080 pump, a model RI-2031 refractive index detector, a model AS-2055 autosampler and a model CO-2060 column oven. ChromNAV Chromatography Data System was used as software. Sugars were separated on a HyperRez XP Carbohydrate $\mathrm{Ca}^{++}$analytical column $(7.7 \times$ $300 \mathrm{~mm}$, ThermoScientific, Waltham, MA, USA) operating at $80^{\circ} \mathrm{C}$. Isocratic elution was effected using water at a flow rate of $0.6 \mathrm{~mL} / \mathrm{min}$. The peaks were identified by comparing the retention time with those of standard compounds. To calculate the concentrations in the extract, a calibration curve was drawn for four solutions of known concentration in water.

\section{Determination of total phenols in plant material}

The concentration of total phenols was determined by the Folin-Ciocalteau (FC) assay with gallic acid as calibration standard, using a Shimadzu UV-1800 spectrophotometer (Shimadzu Corp., Columbia, MD, USA). The FC assay was performed by pipetting $200 \mu \mathrm{L}$ of plant extract (obtained as described above for sugars analysis) into a $10-\mathrm{mL}$ PP tube. This operation was followed by addition of $1 \mathrm{~mL}$ of Folin-Ciocalteau's reagent. The mixture was vortexed for 20 to $30 \mathrm{~s}$. Eight hundred microliters of sodium carbonate solution $(20 \%$ $w / v)$ was added to the mixture $5 \mathrm{~min}$ after the addition of the FC reagent. This was recorded as time zero; the mixture was then vortexed for 20 to $30 \mathrm{~s}$ after addition of sodium carbonate. After $2 \mathrm{~h}$ at room temperature, the absorbance of the colored reaction product was measured at $765 \mathrm{~nm}$. The total phenols concentration in the extracts was calculated from a standard calibration curve obtained with different concentrations of gallic acid, ranging from 0 to $600 \mu \mathrm{g} \mathrm{mL}{ }^{-1}$. Results were expressed as milligrams of gallic acid equivalent per kilogram of fresh weight [24]. 


\section{Determination of total antioxidant activity by ferric reducing antioxidant power}

The assay was based on the methodology of Benzie and Strain [25]. Ten grams of plant material was homogenized in $20 \mathrm{~mL}$ of HPLC grade methanol using an UltraTurrax tissue homogenizer (Takmar, Cincinnati, OH, USA) at moderate speed (setting of 60) for $30 \mathrm{~s}$. The ferric-reducing antioxidant power (FRAP) reagent was freshly prepared, containing $1 \mathrm{mM}$ 2,4,6-tripyridyl-2triazine (TPTZ) and $2 \mathrm{mM}$ ferric chloride in $0.25 \mathrm{M}$ sodium acetate buffer at $\mathrm{pH}$ 3.6. One hundred microliters of the methanol extract was added to $1,900 \mu \mathrm{L}$ of FRAP reagent and accurately mixed. After leaving the mixture at $20^{\circ} \mathrm{C}$ for $4 \mathrm{~min}$, the absorbance was determined at $593 \mathrm{~nm}$. Calibration was against a standard curve (0 to $1,200 \mu \mathrm{g} \mathrm{mL} \mathrm{m}^{-1}$ ferrous ion) obtained by the addition of freshly prepared ammonium ferrous sulfate. FRAP values were calculated as microgram per milliliter ferrous ion (ferric-reducing power) and are presented as milligram per kilogram of $\mathrm{Fe}^{2+\mathrm{E}}$ (ferrous ion equivalent).

\section{Extraction and determination of ascorbic acid}

After harvest, the samples were immediately stored at $-80^{\circ} \mathrm{C}$ before analysis. Five-gram samples were homogenized until uniform consistency in a meta-phosphoric acid and acetic acid solution. This solution was used for the ascorbic acid extraction after quantitative reduction of 2,6-dichlorophenolindophenol dyestuff by ascorbic acid and extraction of the excess dyestuff using xylene. The excess of ascorbic acid was measured at $500 \mathrm{~nm}$ in a Shimadzu UV 160A spectrophotometer (Shimadzu Corp., Columbia, MD, USA) and compared with a vitamin C reference standard (ISO/6557-2-1984 method).

\section{Capsaicin and dihydrocapsaicin determination}

Fresh leaves and green and red peppers (2 g) were extracted with $20 \mathrm{~mL}$ of acetone, followed by homogenization with an Ultra-Turrax T 25 (IKA, Staufen, Germany) for $30 \mathrm{~s}$ at 17,500 rpm. The extract was filtered with filter paper and then through regenerated cellulose syringe filters $(0.45 \mu \mathrm{m})$. The analysis of the extracts was performed using an HPLC system (X-LC Jasco Co., Tokyo, Japan) equipped with a DAD detector (MD-2015, Jasco Co., Tokyo, Japan) and autosampler (AS-2055, Jasco Co., Tokyo, Japan). Samples $(20 \mu \mathrm{L}$ injection volume) were separated on a Tracer Extrasil ODS-2 $(250 \times 45 \mathrm{~mm}, 5 \mu \mathrm{m}$, Teknokroma, Barcelona, Spain) HPLC column. The mobile phase consisted of two solvents: water (A) and methanol (B) $(50: 50, v / v)$. Isocratic elution for $10 \mathrm{~min}$ was used, followed by gradient elution $50 \%$ to $90 \%$ B for $10 \mathrm{~min}$. The flow rate was $1 \mathrm{~mL} /$ min and column temperature was $25^{\circ} \mathrm{C}$. Detection was set at $278 \mathrm{~nm}$. To calculate the concentrations in the extract, a calibration curve was drawn for four solutions of known concentration in acetone.

\section{Data analysis}

The data represent the means of measurements from five plants per treatment, each representing one biological replicate. Analysis of variance (ANOVA) was performed using the SPSS for Windows software, version 18.0 (SPSS, Chicago, IL, USA) and was followed by pairwise post hoc analyses (Student-Newman-Keuls test) to determine which means differed significantly at $p<0.05$.

\section{Results}

\section{Characterization of biostimulants and hormones} quantification

The chemical characteristics of RG and AH are reported in Table 1. The values of $\mathrm{pH}$ were acid in both cases: 2.9 for RG and 5.9 for $\mathrm{AH}$. Total carbon (TC) was $1.23 \%$ for $\mathrm{RG}$ and 18.8 for $\mathrm{AH}$. The total sugars content was $5,700 \mathrm{mg} / \mathrm{L}$ for RG and 4,642 mg/L for AH. The level of total phenols in RG and $\mathrm{AH}$ was appreciable: 970 and 2,576 mg/L, respectively. Hormone determination via ELISA assay evidenced an IAA concentration of $2.92 \mathrm{nmol} \mathrm{mg}$ carbon $^{-1}$ and an IPA concentration of

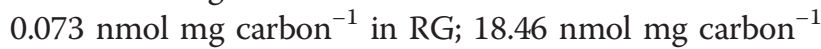

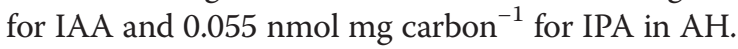

\section{Effects of RG and AH on growth parameters}

To establish the stimulatory effects of RG and AH on growth, the fresh weight of leaves and peppers was measured (Figures 1A,B). At the first sampling time, RG and $\mathrm{AH}$ increased the leaf biomass at both tested rates. More specifically, RG at the lower and $\mathrm{AH}$ at the higher rate enhanced leaf weight $(+68 \%$ and $+165 \%)$ in comparison to untreated plants. The weight of green peppers showed a similar trend as the leaves, but both RG and AH rates, reduced the biomass of red peppers.

At the second sampling time (Figure 1B), the opposite trend of leaf and pepper biomass production in relation to the application of biostimulants was observed: RG and $\mathrm{AH}$ addition weakly stimulated the leaf biomass, decreased green pepper weight, and significantly increased the red pepper weight.

Table 1 Chemical properties and hormone content of red grape (RG) and alfalfa hydrolyzate (AH) products

\begin{tabular}{llll}
\hline Property & Unit & RG & AH \\
\hline pH & & 2.9 & 5.9 \\
Total carbon (TC) & $\%$ & 1.23 & 18.8 \\
Total sugars & $\mathrm{mg} \mathrm{L}^{-1}$ & 5,700 & 4,642 \\
Total phenols & $\mathrm{mg} \mathrm{L}^{-1}$ & 970 & 2,576 \\
Indole-3-acetic acid (IAA) & $\mathrm{nmol} \mathrm{mg} \mathrm{carbon}^{-1}$ & 2.92 & 18.46 \\
Isopentenyladenosine (IPA) & $\mathrm{nmol} \mathrm{mg} \mathrm{carbon}$ & 0.073 & 0.055 \\
\hline
\end{tabular}




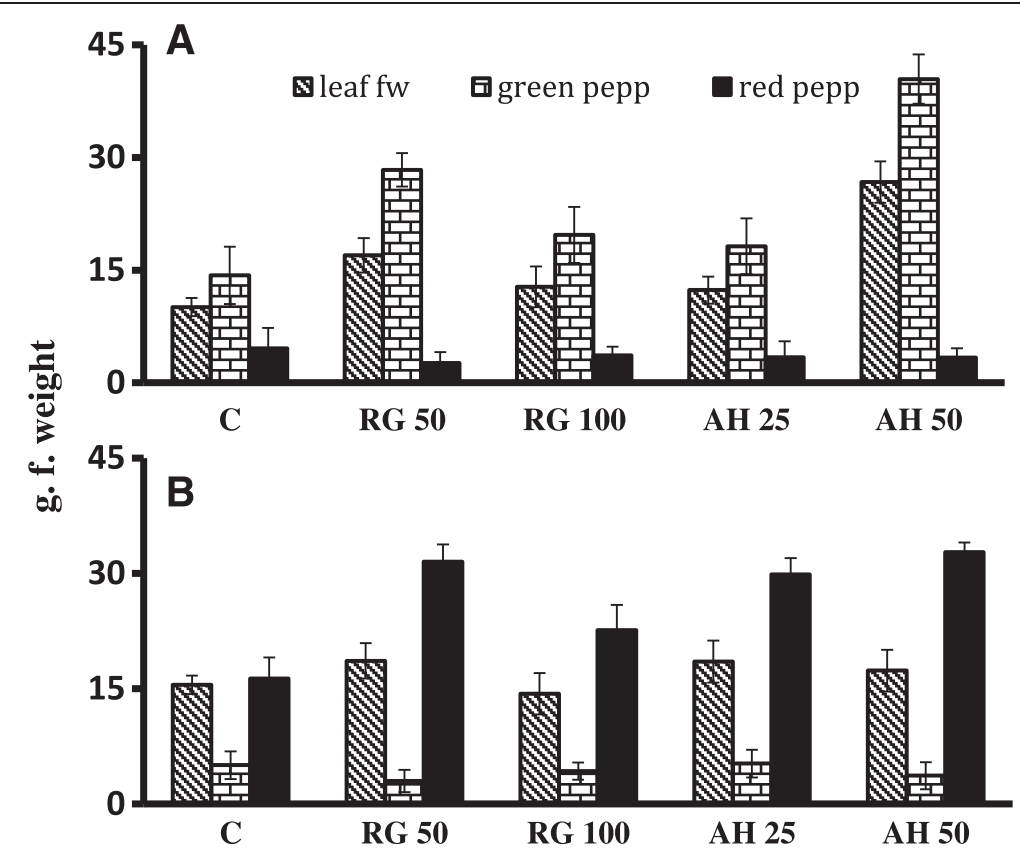

Figure 1 Effect of spray-solutions with red grape skin extract (RG) or alfalfa hydrolyzate (AH). On fresh weight of leaf and green and red fruits of hot pepper. (A) first harvest (flowering); (B) second harvest (maturity); error bars represent \pm standard deviation $(n=5)$.

Table 2 reports the number of peppers at different maturity stages. Application of RG and AH at both tested doses increased the number of peppers in comparison to the untreated plants at flowering stage. Specifically, the amount of green peppers increased $(+104 \%$ and $+175 \%)$ when RG and AH were furnished at the lower and at the higher rate, respectively. The number of red peppers was slightly enhanced after biostimulants treatment. On the contrary, at maturity stage (Table 2), both RG dosages

Table 2 Effect of RG and AH on green and red pepper number at flowering and maturity

\begin{tabular}{llllll}
\hline Treatment & $\mathbf{m L ~ L}^{-1}$ & Flowering & $\%$ & Maturity & $\%$ \\
\hline Green pepper number & & & & & \\
Control & - & $18.2 \pm 1.2 \mathrm{c}$ & 100 & $4.3 \pm 0.3 \mathrm{c}$ & 100 \\
RG & 50 & $37.1 \pm 1.7 \mathrm{~b}$ & 204 & $5.1 \pm 0.4 \mathrm{~b}$ & 119 \\
RG & 100 & $21.5 \pm 1.1 \mathrm{c}$ & 118 & $5.0 \pm 0.1 \mathrm{~b}$ & 116 \\
$\mathrm{AH}$ & 25 & $20.2 \pm 0.8 \mathrm{c}$ & 111 & $6.0 \pm 0.4 \mathrm{a}$ & 140 \\
$\mathrm{AH}$ & 50 & $50.1 \pm 6.1 \mathrm{a}$ & 275 & $4.2 \pm 0.6 \mathrm{c}$ & 98 \\
Red pepper number & & & & & \\
Control & - & $4.3 \pm 0.3 \mathrm{a}$ & 100 & $18.3 \pm 0.9 \mathrm{c}$ & 100 \\
RG & 50 & $2.1 \pm 0.1 \mathrm{~b}$ & 49 & $32.5 \pm 1.6 \mathrm{~b}$ & 178 \\
RG & 100 & $4.3 \pm 0.3 \mathrm{a}$ & 100 & $30.1 \pm 1.5 \mathrm{~b}$ & 164 \\
AH & 25 & $4.2 \pm 0.5 \mathrm{a}$ & 98 & $36.0 \pm 1.8 \mathrm{a}$ & 197 \\
AH & 50 & $4.1 \pm 0.1 \mathrm{a}$ & 95 & $37.0 \pm 1.8 \mathrm{a}$ & 202 \\
\hline
\end{tabular}

Data represent the means of measurements using five plants per treatment. Different letters in the same column indicate significant differences between treatments $(p<0.05)$ according to Student-Newman-Keuls test. increased the number of green and red peppers with increments ranging from $+19 \%$ to $+78 \%$ in comparison to the control plants. The application of $\mathrm{AH}$ to plants induced the greatest effect on red peppers, regardless of the tested dose.

\section{Effects of $\mathrm{RG}$ and $\mathrm{AH}$ on reducing sugars concentration}

The effects of $\mathrm{RG}$ and $\mathrm{AH}$ on pepper plants were first investigated by determining the concentration of reducing sugars (Table 3). At the flowering phase, there was an increase in sugar concentration in leaves of pepper plants sprayed with RG, at both doses. More specifically, the increase was by about $111 \%$ at the lower and by about $75 \%$ at the higher RG dose. With respect to green peppers, the concentration of sugars was enhanced by the two treatments at the maturity stage. In particular, RG increased the sugars concentration by $71 \%$ and $354 \%$ at the lower and higher rates, respectively. At the same stage, the $\mathrm{AH}$ addition increased the reducing sugars with increments of $77 \%$ and $+50 \%$ in red peppers of plants treated with the lower and higher rates, respectively.

\section{Total phenols, FRAP, and ascorbic acid concentration}

The samples were analyzed for total phenolic compounds, which are mainly responsible for the antioxidant activity of plant extracts. Different concentrations of total phenols were found in plants in response to RG and $\mathrm{AH}$ addition (Table 4). Their amount was significantly enhanced in leaves of plants treated with $\mathrm{AH}$, at 
Table 3 Effect of RG and AH on reducing sugar content in pepper plants at flowering

\begin{tabular}{|c|c|c|c|c|c|}
\hline \multirow[t]{3}{*}{ Treatment } & & \multicolumn{4}{|c|}{ Reducing sugars (glucose+fructose) } \\
\hline & & $\mu \mathrm{g}$ & (\%) & $\mu \mathrm{g}$ & (\%) \\
\hline & & \multicolumn{2}{|l|}{ Flowering } & \multicolumn{2}{|l|}{ Maturity } \\
\hline \multicolumn{6}{|l|}{ Leaf } \\
\hline C & - & $4.19 \pm 1.12 \mathrm{c}$ & 100 & $19.37 \pm 1.05 a$ & 100 \\
\hline RG & 50 & $8.83 \pm 1.78 b$ & 211 & $16.61 \pm 0.89 b$ & 86 \\
\hline RG & 100 & $7.34 \pm 0.54 b$ & 175 & $17.46 \pm 1.13 \mathrm{ab}$ & 90 \\
\hline $\mathrm{AH}$ & 25 & $7.00 \pm 1.82 b$ & 167 & $18.39 \pm 1.23 a b$ & 95 \\
\hline $\mathrm{AH}$ & 50 & $14.89 \pm 2.45 a$ & 355 & $16.35 \pm 0.97 b$ & 84 \\
\hline \multicolumn{6}{|c|}{ Green peppers } \\
\hline C & - & $17.56 \pm 2.33 b$ & 100 & $2.64 \pm 0.23 c$ & 100 \\
\hline RG & 50 & $28.77 \pm 2.59 a$ & 164 & $4.52 \pm 0.36 b$ & 171 \\
\hline RG & 100 & $14.28 \pm 1.24 b$ & 81 & $11.99 \pm 0.99 a$ & 454 \\
\hline $\mathrm{AH}$ & 25 & $10.82 \pm 0.78 c$ & 62 & $9.47 \pm 0.85 a$ & 359 \\
\hline $\mathrm{AH}$ & 50 & $32.89 \pm 3.01 c$ & 187 & $5.66 \pm 0.68 b$ & 214 \\
\hline \multicolumn{6}{|c|}{ Red peppers } \\
\hline C & - & $23.87 \pm 3.48 a$ & 100 & $67.12 \pm 4.66 d$ & 100 \\
\hline RG & 50 & $13.84 \pm 1.55 c$ & 58 & $123.80 \pm 7.48 \mathrm{a}$ & 184 \\
\hline RG & 100 & $19.14 \pm 2.95 b$ & 80 & $84.09 \pm 5.51 \mathrm{c}$ & 125 \\
\hline $\mathrm{AH}$ & 25 & $17.68 \pm 2.66 b$ & 74 & $118.86 \pm 6.36 a$ & 177 \\
\hline $\mathrm{AH}$ & 50 & $17.48 \pm 2.59 b$ & 73 & $100.83 \pm 5.88 b$ & 150 \\
\hline
\end{tabular}

Data represent the means of measurements using five plants per treatment. Different letters in the same column indicate significant differences between treatments $(p<0.05)$ according to Student-Newman-Keuls test. Data are expressed as $\mu$ g reducing sugars per leaf or pepper dry weight.

both tested rates. The increments ranged from $+5 \%$ in leaves of plants sprayed with RG at the lower rate to $+58 \%$ in those supplied with $\mathrm{AH}$ at the higher rate, in comparison to the untreated plants. In both red and green peppers, the amount of total phenols increased after RG treatment at the higher dose and after application of $\mathrm{AH}$ at both tested doses. More specifically, the highest values were observed in red $(+55 \%)$ and green peppers $(+54 \%)$ of plants sprayed with RG at the higher dose.

An increase in FRAP was found in leaves of pepper plants sprayed with $\mathrm{AH}$ at both tested rates, with values ranging from $+22 \%$ to $+24 \%$ compared to the controls (Table 4). The stimulation of FRAP in green peppers by $\mathrm{AH}$ was much more pronounced $(+61 \%$ at the lower and $+33 \%$ at the higher rate). On the contrary, the effect of biostimulants on red peppers led to a weak increment of FRAP. The application of biostimulants caused a slight increase in the ascorbic acid concentration, with the highest values observed in leaves and green peppers of plants sprayed with $\mathrm{AH}$ at the lower dose $(+18 \%$ and $+20 \%$, respectively).

Overall, the content of phenolics, ascorbic acid, and FRAP were more enhanced at the second sampling time corresponding to plant maturity (Table 5). The greatest increments of total phenols were observed in leaves $(+45 \%)$ and green peppers $(+140 \%)$ of plants treated with both AH doses. The FRAP in peppers was increased after $\mathrm{AH}$ treatment, with values ranging from $+59 \%$ in red peppers at the higher rate to $+27 \%$ in green peppers at the lower one. The ascorbic acid concentration was enhanced in leaves of plants supplied with RG at the lower $(+17 \%)$ and higher $(+24 \%)$ dose, as well as after treatment with the lower dose of $\mathrm{AH}(+37 \%)$.

With respect to red peppers, the greatest increase of ascorbic acid $(+45 \%)$ was evident in plants supplied with RG at the higher dose, while in green pepper both AH and RG at all the tested doses increased ascorbic acid concentration. Specifically, the greater increments were observed in plants treated with RG at the higher rate $(+106 \%)$ and with $\mathrm{AH}$ at the lower rate $(+153 \%)$.

\section{Capsaicin and dihydrocapsaicin determination}

Capsaicin was not detected in leaves of pepper plants (Table 6). In red peppers, RG at the lower rate determined an enhancement of capsaicin content $(+24 \%)$ in comparison to untreated plants, while $\mathrm{AH}$ increased the amount of this compound at both tested doses: $+30 \%$ and $+37 \%$ at the lower and higher rate, respectively. On the contrary, in green peppers, biostimulants did not stimulate the synthesis of capsaicin (Table 6). The dihydrocapsaicin concentration was enhanced in leaves of RG- and AH-treated plants, with increments ranging from $+117 \%$ in plants supplied with $R G$ at the lower rate to $+98 \%$ in plants sprayed with $\mathrm{AH}$ at the same dose. With respect to the concentration of this metabolite in red and green peppers, there was only an increase of dihydrocapsaicin in the case of red peppers on plants with $\mathrm{AH}$ added at the higher dose $(+46 \%)$. At the second sampling time, neither capsaicin nor dihydrocapsaicin were present in leaves, while their concentration was increased in red peppers by the two biostimulants at both rates, with increments ranging from $+162 \%$ to $+341 \%$. RG and AH treatments increased these two metabolites to a lesser extent in green peppers.

\section{Discussion}

A number of researches have described the positive effects of biostimulants on plant growth and physiology. In particular, previous studies reported the improvement of pepper plant biomass and yield by either natural biostimulants [26] or humic substances from composted sludge [13]. Accordingly, RG and AH application to plants resulted in increased leaf biomass and weight of green peppers at the flowering stage, as well as in increased red pepper number and growth at maturity. The stimulation of plant growth by RG and $\mathrm{AH}$ was possibly due to their content in IAA and IPA, as both hormones 
Table 4 Effect of biostimulants on total phenols, FRAP and ascorbic acid in pepper plants at flowering

\begin{tabular}{|c|c|c|c|c|c|c|c|}
\hline \multirow[t]{2}{*}{ Treat } & \multirow[b]{2}{*}{$\mathrm{mL} \mathrm{L}^{-1}$} & \multicolumn{2}{|l|}{ Total phenols } & \multicolumn{2}{|l|}{ FRAP } & \multicolumn{2}{|l|}{ Ascorbic acid } \\
\hline & & $\mathrm{mg} \mathrm{GAE} \mathrm{kg}^{-1} \mathrm{fw}$ & $\overline{(\%)}$ & $\mathrm{mg} \mathrm{Fe}{ }^{2+} \mathrm{E} \mathrm{kg}^{-1} \mathrm{fw}$ & $\overline{(\%)}$ & $\mathrm{mg} \mathrm{kg}^{-1} \mathrm{fw}$ & $\overline{(\%)}$ \\
\hline \multicolumn{8}{|l|}{ Leaf } \\
\hline C & - & $1,102.1 \pm 60.3 c$ & 100 & $3,042.5 \pm 121.1 b$ & 100 & $1,857.1 \pm 83.1 \mathrm{ab}$ & 100 \\
\hline RG & 50 & $1,161.4 \pm 53.1 \mathrm{c}$ & 105 & $2,907.3 \pm 116.4 b$ & 96 & $1,709.2 \pm 73.1 b$ & 92 \\
\hline RG & 100 & $1,364.4 \pm 65.3 b$ & 124 & $3,211.1 \pm 130.1 b$ & 106 & $1,962.2 \pm 38.4 a$ & 106 \\
\hline $\mathrm{AH}$ & 25 & $1,686.1 \pm 73.1 \mathrm{a}$ & 153 & $3,697.1 \pm 190.1 a$ & 122 & $2,190.4 \pm 93.1 a$ & 118 \\
\hline $\mathrm{AH}$ & 50 & $1,745.1 \pm 80.2 \mathrm{a}$ & 158 & $3,781.3 \pm 173.3 a$ & 124 & $1,906.3 \pm 87.3 a$ & 103 \\
\hline \multicolumn{8}{|c|}{ Red peppers } \\
\hline C & - & $1,081.1 \pm 51.1 \mathrm{c}$ & 100 & $3,090.1 \pm 152.3 b$ & 100 & $1,740.2 \pm 81.1 a$ & 100 \\
\hline RG & 50 & $1,080.2 \pm 38.1 \mathrm{c}$ & 100 & $3,178.3 \pm 120.3 b$ & 103 & $1,677.3 \pm 63.2 b$ & 96 \\
\hline RG & 100 & $1,678.1 \pm 80.7 a$ & 155 & $4,510.5 \pm 220.1 a$ & 146 & $1,754.3 \pm 75.1 \mathrm{ab}$ & 101 \\
\hline $\mathrm{AH}$ & 25 & $1,317.3 \pm 60.1 b$ & 122 & $3,135.2 \pm 130.4 b$ & 101 & $1,905.0 \pm 91.0 \mathrm{a}$ & 110 \\
\hline $\mathrm{AH}$ & 50 & $1,138.3 \pm 60.7 c$ & 105 & $3,280.2 \pm 133.0 b$ & 106 & $1,877.1 \pm 83.1 \mathrm{a}$ & 108 \\
\hline \multicolumn{8}{|c|}{ Green peppers } \\
\hline C & - & $3,621.4 \pm 153.2 b$ & 100 & $1,078.0 \pm 38.2 \mathrm{c}$ & 100 & $1,502.6 \pm 63.1 b$ & 100 \\
\hline RG & 50 & $2,797.2 \pm 110.2 c$ & 77 & $942.4 \pm 40.2 d$ & 87 & $1,687.4 \pm 80.2 \mathrm{a}$ & 112 \\
\hline RG & 100 & $5,590.2 \pm 216.2 a$ & 154 & $1,584.1 \pm 83.8 \mathrm{a}$ & 147 & $1,639.4 \pm 53.2 \mathrm{a}$ & 109 \\
\hline $\mathrm{AH}$ & 25 & $5,559.1 \pm 230.8 a$ & 154 & $1,733.1 \pm 73.1 \mathrm{a}$ & 161 & $1,806.0 \pm 63.2 \mathrm{a}$ & 120 \\
\hline $\mathrm{AH}$ & 50 & $5,439.4 \pm 250.4 a$ & 150 & $1,432.3 \pm 53.2 b$ & 133 & $1,697.0 \pm 80.1 \mathrm{a}$ & 112 \\
\hline
\end{tabular}

Data represent the means of measurements using five plants per treatment. Different letters in the same column indicate significant differences between treatments $(p<0.05)$ according to Student-Newman-Keuls test.

are known to play a pivotal role in plant development and initiation of fruit ripening. In support of this, previous work showed that physiological active concentrations of IAA contained in high molecular-weight humic substances [14] and in an alfalfa-based biostimulant EM [7] accounted for the enhancement of maize biomass production.

The more pronounced growth of pepper plants treated with $\mathrm{RG}$ and $\mathrm{AH}$ was consistent with the reduction in concentration of soluble sugars in leaves at maturity, which could be partially ascribed to the higher consumption of these compounds in the respiratory process. Indeed, biostimulants can induce the activity and gene expression of several enzymes involved in the tricarboxylic acid cycle (TCA), as previously observed in maize plants treated with an alfalfa based-hydrolizate [7]. Additionally, soluble sugars in leaves decreased because of their translocation into the fruits at plant maturity. Sugars provide energy for fruit development [27] and represent a major determinant of fruit quality. Therefore, changes in their composition and content lead to easily perceptible alterations in fruit flavor, which is an important, non-visual attribute for customers [28,29]. In this respect, the higher content of reducing sugars in peppers of plants treated with RG and AH compared to peppers of untreated plants indicated that both biostimulants can efficiently improve the fruit quality.
The increased accumulation of sugars in peppers appeared to be strongly associated to the level of ascorbic acid. Pepper is a good source of this antioxidant compound, which is notoriously involved in the photosynthetic process and in the synthesis of ethylene, gibberellins and anthocyanins, as well as in the control of cell growth and in the reduction of oxidative stress. Research performed on the ascorbate deficient mutant of Arabidopsis thaliana provided evidence that the ascorbic acid biosynthetic pathway starts from glucose, thus underlining a positive relationship between ascorbic acid and sugars concentrations in plants. In agreement with these findings, in the current investigation, the amount of ascorbic acid was enhanced in green peppers by $\mathrm{RG}$ and $\mathrm{AH}$ mainly at the maturity stage of plants, as in the case of soluble sugars. Increased levels of ascorbic acid were also observed in tomato plants treated with a seaweed-based biostimulant [30].

A recent study showed that agro-industrial residues and an alfalfa-based hydrolizate EM could function as biostimulants in agriculture as they increased maize plant yield and resistance to stress conditions through the enhancement of phenol production $[15,16]$. In particular, these biostimulants were able to induce the activity of the PAL enzyme, which is a notorious key regulator of phenol compound biosynthesis [16]. Possibly, RG and AH enhanced 
Table 5 Effect of biostimulants on total phenols, FRAP and ascorbic acid in pepper plants at maturity

\begin{tabular}{|c|c|c|c|c|c|c|c|}
\hline \multirow[t]{2}{*}{ Treatment } & \multirow{2}{*}{$\mathrm{m}_{-1}^{\mathrm{mL}} \mathrm{L}$} & \multicolumn{2}{|l|}{ Total phenols } & \multicolumn{2}{|l|}{ FRAP } & \multicolumn{2}{|l|}{ Ascorbic acid } \\
\hline & & $\mathrm{mg} \mathrm{GAE} \mathrm{kg}{ }^{-1} \mathrm{fw}$ & $\overline{(\%)}$ & $\mathrm{mg} \mathrm{Fe}^{2+} \mathrm{E} \mathrm{kg}^{-1} \mathrm{fw}$ & $(\%)$ & $\mathrm{mg} \mathrm{kg}^{-1} \mathrm{fw}$ & $\overline{(\%)}$ \\
\hline \multicolumn{8}{|l|}{ Leaf } \\
\hline C & - & $1,318 \pm 55.7 \mathrm{c}$ & 100 & $3,620.4 \pm 62.3 c$ & 100 & $528.3 \pm 42.3 c$ & 100 \\
\hline$R G$ & 50 & $1,784 \pm 80.3 a b$ & 135 & $3,740.2 \pm 72.2 b$ & 103 & $618.4 \pm 56.3 d$ & 117 \\
\hline$R G$ & 100 & $1,649 \pm 60.2 b$ & 125 & $3,634.2 \pm 48.4 c$ & 100 & $652.7 \pm 25.2 b$ & 124 \\
\hline $\mathrm{AH}$ & 25 & $1,906 \pm 62.84 a$ & 145 & $3,890.0 \pm 53.3 a$ & 107 & $723.3 \pm 38.3 a$ & 137 \\
\hline $\mathrm{AH}$ & 50 & $1,894 \pm 82.2 \mathrm{a}$ & 144 & $3,990.1 \pm 25.8 a$ & 110 & $525.4 \pm 52.2 c$ & 100 \\
\hline \multicolumn{8}{|l|}{ Red peppers } \\
\hline C & - & $1,196.4 \pm 38.7 c$ & 100 & $4,218.1 \pm 113.2 c$ & 100 & $900.3 \pm 76.7 c$ & 100 \\
\hline$R G$ & 50 & $1,425.5 \pm 82.5 b$ & 119 & $4,610.1 \pm 216.1 c$ & 109 & $1,084.2 \pm 112.1 b$ & 120 \\
\hline$R G$ & 100 & $1,684.4 \pm 32.8 a$ & 141 & $4,748.3 \pm 221.3 c$ & 112 & $1,307.5 \pm 103.0 a$ & 145 \\
\hline $\mathrm{AH}$ & 25 & $1,732.3 \pm 83.1 \mathrm{a}$ & 145 & $5,770.0 \pm 286.3 b$ & 136 & $1,045.1 \pm 128.0 b$ & 116 \\
\hline $\mathrm{AH}$ & 50 & $1,667.1 \pm 77.0 a$ & 139 & $6,721.0 \pm 283.3 a$ & 159 & $1,185.1 \pm 176.3 \mathrm{ab}$ & 131 \\
\hline \multicolumn{8}{|c|}{ Green peppers } \\
\hline C & - & $2,364.4 \pm 101.2 d$ & 100 & $12,010.7 \pm 421.6 \mathrm{c}$ & 100 & $498.5 \pm 56.2 d$ & 100 \\
\hline RG & 50 & $3,447.4 \pm 128.3 c$ & 146 & $12,749.5 \pm 526.3 c$ & 106 & $705.3 \pm 123.0 \mathrm{c}$ & 142 \\
\hline$R G$ & 100 & $4,320.5 \pm 222.1 b$ & 183 & $13,645.8 \pm 628.3 b c$ & 113 & $1,029.5 \pm 101.81 b$ & 206 \\
\hline $\mathrm{AH}$ & 25 & $5,670.0 \pm 271.5 \mathrm{a}$ & 240 & $15,260.1 \pm 623.5 a$ & 127 & $1,263.2 \pm 112.21 \mathrm{a}$ & 253 \\
\hline $\mathrm{AH}$ & 50 & $5,678.0 \pm 215.4 a$ & 240 & $14,539.1 \pm 618.6 a$ & 121 & $1,021.1 \pm 116.07 b$ & 205 \\
\hline
\end{tabular}

Data represent the means of measurements using five plants per treatment. Different letters in the same column indicate significant differences between treatments $(p<0.05)$ according to Student-Newman-Keuls test.

the phenol content of peppers, especially at the maturity stage, by acting on PAL enzyme, too. This increase in phenolic compounds was likely responsible for the higher values of FRAP activity measured in peppers, as supported by a number of authors [31,32].

Other additional positive effects of $\mathrm{AH}$ and $\mathrm{RG}$ in pepper included the increased number of red fruits and stimulation of capsaicinoid production. In the first case, the higher number of fruits indicated an acceleration of the phenological development in plants supplied with the two biostimulants. This kind of 'priming' can be very important in countries with a temperate climate, where the cultivation period of peppers is relatively short and early cold temperatures in autumn can have a negative effect on flower and fruit development, as well as on fruit quality [33]. Priming may also result in economic and environmental benefits, since it can contribute to a reduction in the number of pesticide applications needed for the control of pepper pests and diseases [17].

The induction of capsaicinoid synthesis was particularly remarkable at the maturity stage of plants, probably because of the cumulative effects of the treatments. Capsaicin is one of the most important pepper metabolites as it is responsible for the fruit pungency. The increase of this compound in treated plants is of practical interest and has great relevance in medicine because capsaicin possesses analgesic and anti-inflammatory activities [34].

Although the RG and $\mathrm{AH}$ induced similar responses in pepper plants, the degree of each response could vary depending on the type of biostimulant. Differences in effectiveness between RG and AH could be related to the characteristics of the starting matrixes and/or to the industrial processes employed for their production. The cool-extraction method used to produce RG was had the advantage of preserving the organoleptic properties of the raw materials [21], while the hydrolytic process used for $\mathrm{AH}$ production could cause chemical changes in thermolabile bioactive compounds [35]. Moreover, the effectiveness of RG and AH could be in part due to their content in IAA and IPA and in part to the presence of compounds with known biological activity, such as phenols.

\section{Conclusions}

Several studies investigate the effects of biostimulants originated from different sources on the morphological and physiological parameters of plants. The novelty of this research is the attention paid to the effects of $\mathrm{RG}$ and $\mathrm{AH}$ on the nutritional features of fruits in consideration of the increased demand for functional foods by consumers. The obtained results demonstrated the effectiveness of RG and 
Table 6 Effect of biostimulants on capsaicin and dihydrocapsaicin concentration in pepper plants at flowering and maturity

\begin{tabular}{|c|c|c|c|c|c|c|c|c|c|}
\hline \multirow[t]{3}{*}{ Treatment } & \multirow[t]{3}{*}{$\mathrm{mL} \mathrm{L}^{-1}$} & \multicolumn{2}{|l|}{ Capsaicin } & \multicolumn{2}{|c|}{ Dihydrocapsaicin } & \multicolumn{2}{|l|}{ Capsaicin } & \multicolumn{2}{|c|}{ Dihydrocapsaicin } \\
\hline & & $\left(\mu g^{-1} d w\right)$ & $\overline{(\%)}$ & $\overline{\left(\mu g^{-1} d w\right)}$ & $\overline{(\%)}$ & $\left(\mu g^{-1} d w\right)$ & $\overline{(\%)}$ & $\overline{\left(\mu g^{-1} d w\right)}$ & (\%) \\
\hline & & \multicolumn{4}{|l|}{ Flowering } & \multicolumn{4}{|l|}{ Maturity } \\
\hline \multicolumn{10}{|l|}{ Leaf } \\
\hline C & - & - & - & $0.91 \pm 0.02 b$ & 100 & - & - & - & - \\
\hline$R G$ & 50 & - & - & $1.98 \pm 0.10 \mathrm{a}$ & 217 & - & - & - & - \\
\hline RG & 100 & - & - & $1.80 \pm 0.08 a$ & 198 & - & - & - & - \\
\hline $\mathrm{AH}$ & 25 & - & - & $1.80 \pm 0.06 a$ & 198 & - & - & - & - \\
\hline $\mathrm{AH}$ & 50 & - & - & $0.76 \pm 0.021 c$ & 84 & - & - & - & - \\
\hline \multicolumn{10}{|l|}{ Red peppers } \\
\hline C & - & $155.4 \pm 7.2 c$ & 100 & $42.8 \pm 1.18 b$ & 100 & $48.3 \pm 3.8 \mathrm{~d}$ & 100 & $17.2 \pm 0.6 c$ & 100 \\
\hline RG & 50 & $192.0 \pm 8.3 b$ & 124 & $34.7 \pm 1.53 c$ & 80 & $321.4 \pm 12.1 \mathrm{a}$ & 668 & $70.2 \pm 12.5 a$ & 394 \\
\hline$R G$ & 100 & $124.6 \pm 5.8 d$ & 81 & $26.3 \pm 1.12 d$ & 61 & $261.0 \pm 61.6 b$ & 544 & $50.3 \pm 11.4 b$ & 281 \\
\hline $\mathrm{AH}$ & 25 & $201.1 \pm 6.2 \mathrm{a}$ & 130 & $38.1 \pm 1.76 b$ & 91 & $220.1 \pm 52.5 c$ & 459 & $46.3 \pm 12.0 \mathrm{~b}$ & 262 \\
\hline $\mathrm{AH}$ & 50 & $211.2 \pm 7.8 a$ & 137 & $62.7 \pm 3.83 a$ & 146 & $335.0 \pm 72.1 a$ & 696 & $78.2 \pm 14.1 \mathrm{a}$ & 441 \\
\hline \multicolumn{10}{|c|}{ Green peppers } \\
\hline C & - & $179.3 \pm 18.3 a$ & 100 & $46.35 \pm 11.2 \mathrm{a}$ & 100 & $89.0 \pm 13.2 \mathrm{c}$ & 100 & $27.2 \pm 1.9 c$ & 100 \\
\hline$R G$ & 50 & $183.1 \pm 17.5 \mathrm{a}$ & 102 & $40.14 \pm 11.7 b$ & 87 & $162.1 \pm 25.7 a$ & 182 & $28.3 \pm 1.2 c$ & 106 \\
\hline$R G$ & 100 & $152.2 \pm 15.4 b$ & 85 & $31.53 \pm 11.8 c$ & 68 & $157.2 \pm 25.3 a$ & 176 & $54.5 \pm 12.8 \mathrm{a}$ & 199 \\
\hline $\mathrm{AH}$ & 25 & $153.3 \pm 15.8 b$ & 86 & $38.74 \pm 11.5 b$ & 84 & $98.2 \pm 12.8 c$ & 111 & $25.4 \pm 13.1 \mathrm{c}$ & 93 \\
\hline $\mathrm{AH}$ & 50 & $160.2 \pm 13.2 b$ & 89 & $47.27 \pm 12.16 a$ & 102 & $117.1 \pm 16.2 b$ & 132 & $43.6 \pm 15.5 b$ & 161 \\
\hline
\end{tabular}

Data represent the means of measurements using five plants per treatment. Different letters in the same column indicate significant differences between treatments $(p<0.05)$ according to Student-Newman-Keuls test.

$\mathrm{AH}$ in improving the nutritional value of peppers by increasing their content in phytochemicals with nutritional value.

\section{Competing interests}

The authors declare that they have no competing interests.

\section{Authors' contributions}

AE carried out the laboratory studies, drafted the manuscript, and made the corrections. CN and SS carried out the laboratory studies. PS participated in the drafted the manuscript. MS helped to draft the manuscript. SN conceived of the study, participated in its design and coordination, and helped to draft the manuscript. All authors read and approved the final manuscript.

\section{Acknowledgement}

This research was funded by a grant from the ILSA company Arzignano, Vicenza, to Padua University.

Received: 13 December 2014 Accepted: 31 March 2015

Published online: 24 April 2015

\section{References}

1. Giardini L (2004) Productivity and sustainability of different cropping systems. Patron (Ed.) BO, pp. 1-359

2. Taylor AW, Coveney J, Ward PR, Dal Grande E, Mamerow L, Henderson J, Meyer SB (2012) The Australian food and trust survey: demographic indicators associated with food safety and quality concerns. Food Control 25:476-483

3. Menichini F, Tundis R, Bonesi M, Loizzo MR, Conforti F, Statti G, De Cindio B, Houghton PJ (2009) The influence of fruit ripening on the phytochemical content and biological activity of Capsicum chinensis Jaqc. cv habanero. Food Chem 114:553-560

4. Mueller M, Hobiger S, Jungbauer A (2010) Anti-inflammatory activity of extracts from fruits, herbs and spices. Food Chem 122:987-996

5. Ahmad P, Ashraf M, Younis M, Hu X, Kumar A, Akram NA, Al-Qurainy F (2012) Role of transgenic plants in agriculture and biopharming. Biotech Adv 30:524-540

6. Sherlock R, Morrey JD (2002) Ethical issues in biotechnology. Rowman and Littlefield. Publishers, Inc. Lanham, MD, Lanham MD

7. Schiavon M, Ertani A, Nardi S (2008) Effects of an alfalfa protein hydrolysate on the gene expression and activity of enzymes of TCA cycle and N metabolism in Zea mays L. J Agric Food Chem 56:11800-11808

8. Muscolo A, Sidari M, Nardi S (2013) Humic substance: relationship between structure and activity. Deeper information suggests univocal findings. J Geochem Explor 129:57-63

9. Nardi S, Carletti P, Pizzeghello D, Muscolo A (2009) Biological activities of humic substances. In: Senesi N, Xing B, Huang PM (ed) Biophysico-chemical processes involving natural nonliving organic matter in environmental systems. PART I. Fundamentals and impact of mineral-organic-biota interactions on the formation, transformation, turnover, and storage of natural nonliving organic matter (NOM). John Wiley and Sons, Hoboken, NJ, pp 301-335

10. Ertani A, Nardi S, Altissimo A (2013) Review: long-term research activity on the biostimulant properties of natural origin compounds. Acta Hort 1009:181-188

11. Ertani A, Cavani L, Pizzeghello D, Brandellero E, Altissimo A, Ciavatta C, Nardi S (2009) Biostimulant activity of two protein hydrolysates on the growth and nitrogen metabolism in maize seedlings. J Plant Nutr Soil Sci 172:237-244

12. Vaccaro S, Muscolo A, Pizzeghello D, Spaccini R, Piccolo A, Nardi S (2009) Effect of a compost and its water-soluble fractions on key enzymes of nitrogen metabolism in maize seedlings. J Agric Food Chem 57:11267-11276

13. Azcona I, Pascual I, Aguirreolea J, Fuentes M, Garcia-Mina JM, Sanchez-Diaz M (2011) Growth and development of pepper are affected by humic substances derived from composted sludge. J Plant Nutr Soil Sci 174:916-924 
14. Schiavon M, Pizzeghello D, Muscolo A, Vaccaro S, Francioso O, Nardi S (2010) High molecular size humic substances enhance phenylpropanoid metabolism in maize (Zea mays L.). J Chem Ecol 36:662-669

15. Ertani A, Schiavon M, Muscolo A, Nardi S (2013) Alfalfa plant-derived biostimulant stimulates short-term growth of salt stressed Zea mays $\mathrm{L}$. plants. Plant Soil 364:145-158

16. Ertani A, Schiavon M, Altissimo A, Franceschi C, Nardi S (2011) Phenol-containing organic substances stimulate phenylpropanoid metabolism in Zea mays L. J Plant Nutr Soil Sci 3:496-503

17. Pascual I, Azcona I, Morales F, Aguirreolea J, Sanchez-Diaz M (2009) Growth, yield and physiology of verticillium-inoculated pepper plants treated with ATAD and composted sewage sludge. Plant Soil 319:291-306

18. Pascual I, Azcona I, Aguirreolea J, Morales F, Corpas FJ, Palma JM Rellán-Álvarez R, Sánchez-Díaz M (2010) Growth, yield and fruit quality of pepper plants amended with two sanitized sewage sludges. J Agric Food Chemi 58:6951-6959

19. Deli J, Matus Z, Tóth G (2000) Carotenoid composition in the fruits of asparagus officinalis. J Agric Food Chem 48:2793-2796

20. Howard LR, Talcott ST, Brenes CH, Villalon B (2000) Changes in phytochemical and antioxidant activity of selected pepper cultivars (Capsicum species) as influenced by maturity. J Agric Food Chem 48:1713-1720

21. Machado S (2007) Allelopathic potential of various plant species on downy brome: implications for weed control in wheat production. Agron J 99:127-132

22. Arnaldos TL, Muñoz R, Ferrer MA, Calderón AA (2001) Changes in phenol content during strawberry (Fragaria ananassa, cv. Chandler) callus culture. Physiol Plant 113:315-322

23. Meenakshi S, Manicka GD, Tamilmozhi S, Arumugam M, Balasubramanian T (2009) Total flavonoid in vitro antioxidant activity of two seaweeds of Rameshwaram. Global J Pharmacol 3:59-62

24. Nicoletto C, Santagata S, Bona S, Sambo P (2013) Influece of cut number on qualitative traits in different cultivars of sweet basil. Ind Crops Prod 44:465-472

25. Benzie IFF, Strain JJ (1996) The ferric reducing ability of plasma (FRAP) as a measure of "Antioxidant Power": The FRAP essay. Anal. Biochem 239:70-76

26. Paradikovic N, Vinkovic T, Vrcek IV, Zuntar I, Bojic M, Medic-Saric M (2011) Effect of natural biostimulants on yield and nutritional quality: an example of sweet yellow pepper (Capsicum annuum L.) plants. J Sci Food Agric 91:2146-2152

27. Ruan YL (2012) Signaling role of sucrose metabolism in development. Mol Plant 5(4):1-3

28. Awad MA, de Jager A (2002) Influences of air and controlled atmosphere storage on the concentration of potentially healthful phenolics in apples and other fruits. Postharv Biol Technol 27:53-58

29. Giovannoni JJ (2004) Genetic regulation of fruit development and ripening Plant Cell 16:170-S18

30. Zodape ST, Gupta A, Bhandari SC (2011) Foliar application of seaweed as biostimulant for enhancement of yield and quality of tomato (Lycopersicon esculentum Mill.). J Sci Ind Res 70:215-219

31. Oboh G, Ademosun AO (2012) Characterization of the antioxidant properties of phenolic extracts from some citrus peels. J Food Sci Tech 49:729-736

32. Serrano M, Zapata PJ, Castillo S, Guillén F, Martínez-Romero D, Valero D (2010) Antioxidant and nutritive constituents during sweet pepper development and ripening are enhanced by nitrophenolate treatments. Food Chem 118:497-503

33. Polowick PL, Sawhney VD (1985) Temperature effects on male fertility and flower and fruit development in Capsicum annuum L. Scientia Horticulture 25:117-127

34. Govindarajan VS, Sathyanarayana MN (1991) Capsicum production, technology, chemistry and quality. Part V. Impact on physiology, pharmacology, nutrition and metabolism: structure, pungency, pain and desensitization sequences. Crit Rev Food Sci Nutr 29:435-473

35. Buchanan BB, Wilhelm G, Russell $\sqcup$ (2003) Biochemistry \& molecular biology of plants. American Society of Plant Physiologists Publisher, Rockville, Maryland, pp 1044-1100

\section{Submit your manuscript to a SpringerOpen ${ }^{\odot}$ journal and benefit from:}

- Convenient online submission

- Rigorous peer review

- Immediate publication on acceptance

- Open access: articles freely available online

- High visibility within the field

- Retaining the copyright to your article

Submit your next manuscript at springeropen.com 